\title{
Open Mathematics, Traditional Knowledge and Intellectual Property in the era of the fourth industrial revolution: Challenges and Opportunities in Niger.
}

\author{
Ibrahim Sidi Zakari ${ }^{1}$, Sidi Zakari ${ }^{2}$, Sidi Iyé ${ }^{3}$ \\ \{isidizakari@refer.ne ${ }^{1}$ sidizakariibrahim@gmail.com ${ }^{1}$, sidizakari@yahoo.fr ${ }^{2}$, tabtakey@gmail.com ${ }^{3}$ \} \\ Department of Mathematics and Computer Science (Abdou Moumouni University), Office $\mathrm{N}^{\circ} 8$ \\ POBox 10896, Niamey (Niger) ${ }^{1}$, Niger Republic's General Consulate at Djeddah (Saudi Arabia) ${ }^{2}$, \\ Independent inventor and innovator, Tabotaki/Bouza (Niger) ${ }^{3}$
}

\begin{abstract}
This paper aims at investigating the relationships between Traditional Knowledge, Intellectual Property (IP) and Innovation ecosystems in Niger. Our analysis highlighted the need of improving the availability and quality of data and information for ensuring real evidence based decision making. Moreover, empirical facts showed that political will, a legislative framework, vital institutions/infrastructures, IP culture awarness raising, communication, citizen participation, capacity building and public private partnesrhips (to name a few) are necessary for taking advantages of the current IP system in terms of protection, valorisation and continuous improvement of tradition based inventions and innovations. Finally, our case study showed how a scholar from rural area of Niger had used empirical observations (in the early 1950) to invent a mathematical tool for adressing the unavailability of perpetual calendars issue and how (from generation to generation) this invention benefited from IP and lead to: innovations, partnerships, knowledge sharing, cultural and spiritual identity promotion.
\end{abstract}

Keywords: Open Mathematics, Perpetual Gregorian Calendar, Traditional Knowledge Protection, Frugal Innovation, Intellectual Property, Fourth Industrial Revolution, Sustainable Development.

\section{Introduction}

Each society has adopted, over the course of the evolution of its history, methods and devices relating to the control of time, and this for educational, administrative, religious, astronomical, medical, agricultural, economic or civil registration purposes.

To date, the solar and lunar calendars are used worldwide in the management of dates.

One of the major contributions in this context was undoubtedly made by Malam Sidi Iyé, a Muslim scholar born around 1928 in Tabotaki (Niger).

He has never been to Western school and learned in a self-taught way the French terminology and concepts related to the Gregorian calendar. The regular exploitation of the Gregorian (solar) and Hegirian (lunar) calendar allowed him to invent in the 1980s, the calculator, a mathematical algorithm for searching dates; a technological feat based on writing vertically and horizontally and cyclically; such as a representation of the four cardinal points or the revolution of the earth around the sun. The manuscripts of Malam Sidi Iye were also 
influenced by his mastery of Arabic calligraphy as well as the use of Arabic-Indian numbers in his practice of spiritual medecine. Moreover, at a time when the computer did not exist yet, Malam Sidi Iyé could already give mentally and in few seconds, the day corresponding to any date of the Gregorian calendar or the number of days corresponding the month of February for any year. This mental ability allowed him to win several national competitions and also benefit from wide media coverage. To our knowledge, other works relating to the Gregorian calendar had been made by the mathematicians Gauss Carl Friedrich (1777-1855), Lucas Edward (1842-1891), Fourrey Emile (1869-), Bakst Aaron (1900-1962) and Devi Shakuntala (1929-2013), the Indian prodigy who mastered the art of mental arithmetic.

In the early 1990s (see [1]) and after several years of investigation, the Institute for Research in Human Sciences (IRSH) and the Ministry of Industry of Niger in partnership with a committee of international experts decided to support Malam Sidi Iyé in his patent filing procedure with the African Intellectual Property Organization (AIPO), a regional institution created in 1977.

In 2013, the authorities of the Republic of Niger, in this case the Ministry of Youth, Sports and Culture in partnership with other public and private sector structures and NGOs in the education sector, supported the edition of a perpetual calendar (covering 600 years, from 1701 to 2300) based on the works and manuscripts of Malam Sidi Iye [2]. An official ceremony of delivery of this calendar was made to the Presidency of the Republic (in 2014) in the presence of Malam Sidi Iyé and the Head of State S.E Mahamadou Issoufou.

The edition of this perpetual calendar creates many direct and indirect job opportunities (each year), and collaboration with researchers (in Niger and abroad) and particularly raises the importance of IPR for the inventor and his community particularly in Niger where more than $80 \%$ of the population is living in rural areas.

On the other hand, even in 2017, his method of mental dates searching still allows him to challenge users of computers, mobile applications and other search engines.

This context and historical reminder has shown that the traditional knowledge and cultural heritage of a nation is linked to the heart of its identity and to its present and future.

It also helps to answer part of the fundamental question:

How can we promote intellectual property to promote first the development of traditional knowledge as a common good and then allow fair competition in the era of the fourth industrial revolution?

Many authors (including [3], [4], [5]) have previously highlighted the value and importance of protecting Traditional Knowledge (TK) and also the nature of Intellectual Property and its role in TK protection ([6], [7]). Furthermore, the connection between IP and economic development had been investigated in: [8], [9], [10], [11].

Recently, some authors focused on Science, Technology and Innovation Policy ([12], [13]) and as raised in [14], fundamental science, public research, individual entrepreneurship, demand-side and industrial policies, and patents have greatly contributed to the diffusion of the semiconductor, as a breakthrough technology.

Moreover, 3D printing (as a Keydriver of the Fourth industrial revolution) is contributing to small innovative businesses and research outputs prototyping worldwide.

Finally, international IP and Innovation indicators exist for ranking countries performances. 


\section{Key international indicators}

Our investigations identified two international indicators which can be used to compare countries performances and characteristics in terms of Intellectual Property and Global Innovation, namely: The World Intellectual Property Indicators and The Global Innovation Index(GII).

\subsection{The World Intellectual Property Indicators}

The World Intellectual Property Indicators(2016) [15], highlighted the challenge of accessing to data on IP in many countries including Niger.

\subsection{The Global Innovation Index ${ }^{1}$}

The 2017 report of the Global Innovation Index(GII) [16], raised the fact that Niger was among GII economies with the most missing values (22 missing values). Our analysis find out that the sectors of Human capital \& research, Market sophistication, Business sophistication, knowledge and technology outputs, Creative outputs are the most affected by this lack of data or outdated information.

Moreover, despite the availability of General infrastructure; access and use of Information and Communications Technologies (ICTs) represent a weakness which impact negatively the creation of new businesses and Creative outputs (particularly Intangible assets and Online creativity).

\section{National IP Ecosystem's Analysis}

\subsection{Legal Information}

Niger joined the World Intellectual Property Organization(WIPO) in 1975 and is member of the African Intellectual Property Organization (OAPI) at regional level.

The main national IP law is Decree No. 93-027 of March 30, 1993, on Copyright, Neighbouring Rights and Folklore.

Competent national IP offices are respectively: Niger Copyright Office (BNDA, Ministry of Youth, Sport and Culture) and Direction of Innovation and Industrial property (Ministry of Commerce, Industry and Promotion of Young Entrepreneurs).

In terms of Treaty membership ${ }^{2}$, Niger was signatory of 6 WIPO-administered Treaties, 39 IP-related Multilateral Treaties, 2 IP Regional Treaties and 5 Regional Economic Integration Treaties.

\footnotetext{
${ }^{1}$ http://globalinnovationindex.org.

2 http://www.wipo.int/wipolex/en/profile.jsp?code=NE accessed on 16/10/2017
} 


\subsection{Policies and Strategies}

In terms of policy, IP generally focus on Economics, Traditional Knowledge, Global health, Food Security and Climate Change.

The National Agency for Industrial Property and Promotion of Innovation (AN2PI) has for mission: to develop and implement a relationship with the concerned structures, the national policy on industrial property and promotion of innovation; to promote and manage national activities in the field of industrial property and promotion of innovation in liaison with all the institutions working in the field; to monitor at national and international level all issues related to industrial property and the promotion of innovation; to promote the protection and use of industrial property in Niger; promote activities in innovation and technological development in Niger; fight against counterfeiting and coordinate the action of the various involved administrations; to establish and develop co-operation with subregional, regional and international institutions active in the field of industrial property and the promotion of innovation; to ensure the national trade of the African Intellectual Property Organization (AIPO). Our investigation revealed that the national strategy on IP and innovation is not yet available online ${ }^{3}$.

\subsection{Statistical Profil}

Reliable statistics and objective analysis are important for decision-makers in order to assess the real impact of IP-related policies on business, economic or technology trends.

Our data analysis will cover period from 2001 to 2015 based on the WIPO online statistics database (Last updated: 05/2017) for Niger ${ }^{4}$. Figure 1 highlights some components of the Niger IP Statistical Profil (patents, utility models, trademarks, industrial designs). Particularly, when considering the IP Filings (Resident + Abroad, Including Regional) and Economy we can see that from 2001 to 2015, Gross Domestic Product(GDP) and IP Filings have the same increasing trend. Moreover, Patent Applications, Trademark Applications and Registrations came from abroad (in fact resident applications are very neglectable). The pie chart of Patent Applications by Top Fields of Technology(2001-2015) showed the following repartition: Other special machines(10.00\%), Electrical machinery, apparatus, energy $(8.75 \%)$, Biotechnology $(8.75 \%)$, Macromolecular chemistry, polymers(8.75\%), Food chemistry(7.50\%), Computer technology(6.25\%), Pharmaceuticals(6.25\%), Digital communication(5.00\%), Basic materials chemistry(5.00\%), Optics (3.75\%) and Others $(30.00 \%)$. We also remark a lack of data on Patent Grants and unavailability of data on Utility Models Applications. Industrial Design Applications and Registrations were also from Abroad or by Non-Resident. Finally, International Applications via WIPO Administered Treaties seems to be more related to the Patent Cooperation Treaty (PCT) and PCT National Phase Entry (Direct and via Regional Office) was led by applications from Abroad.

\footnotetext{
${ }^{3}$ Based on our investigations on $24 / 10 / 2017$.

${ }^{4}$ http://www.wipo.int/ipstats/en/statistics/country_profile/profile.jsp?code=NE
} 


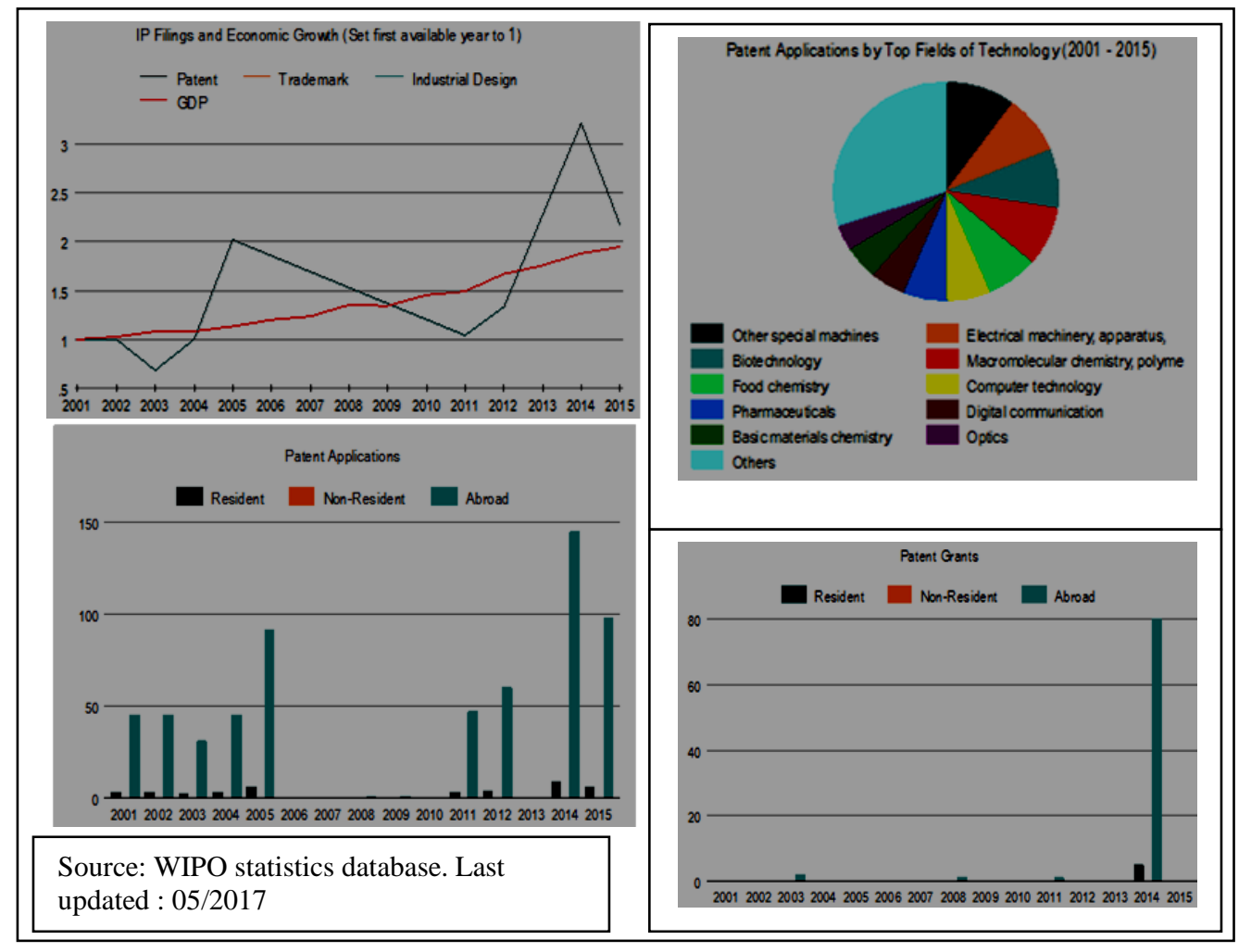

Fig. 1. Overview of IP filings and Economic Growth, Patent Applications, Patent Applications by Top Fields of Technology and Patents Grants for 2001-2015 period.

\subsection{Infrastructure}

Another challenge is the development of interoperable tools, standards, databases, platforms and open data initiatives, which can help in implementing IP related policies and strategies.

\footnotetext{
${ }^{5}$ http://www.wipo.int/tisc/en/search/search_result.jsp?country_code=NE accessed on 15/10/2017
} 


\subsubsection{Technology and Innovation Support Centers ${ }^{6}$ (TISCs)}

At national level, we identified $3 \mathrm{TISCs}^{7}$, strategically located at Maradi (Université Dan Dicko Dankoulodo) and Niamey (Agence Nationale de la Propriété Industrielle et de la Promotion de l'Innovation and Ministère du Développement Industriel de l'Artisanat et du Tourisme $)^{8}$. Details on different technologies and services available ${ }^{9}$ can be found in Table 1.

Table 1. Description of Technologies and Services available at the different TISCs. Source: Authors compilation based on information provided by WIPO online databases.

\begin{tabular}{|c|c|c|c|c|}
\hline \multicolumn{2}{|r|}{ Technologies and Services } & \multicolumn{3}{|c|}{ TISC Name } \\
\hline & & \multirow{2}{*}{\begin{tabular}{|l} 
U3D \\
$\checkmark$ \\
\end{tabular}} & \multirow{2}{*}{\begin{tabular}{|l} 
AN2PI \\
$\checkmark$ \\
\end{tabular}} & \multirow{2}{*}{$\begin{array}{l}\text { MDIAT T } \\
\checkmark \checkmark\end{array}$} \\
\hline \multirow{9}{*}{ Service(s) } & Access to patent and scientific and technical databases & & & \\
\hline & Assistance and advice in using databases & 区 & $\checkmark$ & $\checkmark$ \\
\hline & Assistance and advice on IP management - Commercialization & 区 & $\checkmark$ & 区 \\
\hline & Assistance and advice on IP management - Licensing, technology transfer & $\checkmark$ & $\checkmark$ & $凶$ \\
\hline & Assistance and advice on IP management - Patent drafting, prosecution & $\checkmark$ & $\checkmark$ & 区 \\
\hline & Search - Freedom to operate, clearance & 区 & $\checkmark$ & 区 \\
\hline & Search - Novelty, patentability & $\checkmark$ & $\checkmark$ & 凶 \\
\hline & Search - State of the art & $\checkmark$ & $\checkmark$ & 凶 \\
\hline & Search - Validity & 凶 & $\checkmark$ & 凶 \\
\hline \multirow{8}{*}{ Specialization(s) } & Agriculture and food science & $\checkmark$ & $\checkmark$ & $\checkmark$ \\
\hline & Chemistry and chemical engineering & $\checkmark$ & $\checkmark$ & $\checkmark$ \\
\hline & Civil engineering & $\checkmark$ & 区 & $\checkmark$ \\
\hline & Electrical and electronic engineering & $\checkmark$ & 区 & $\checkmark$ \\
\hline & Health and life sciences & $\checkmark$ & $\checkmark$ & 区 \\
\hline & Information and communication technology & $\checkmark$ & 凶 & $凶$ \\
\hline & Mechanical engineering & $\checkmark$ & $\checkmark$ & 区 \\
\hline & Other & $\checkmark$ & 凶 & $凶$ \\
\hline Language(s) & & French & French & French \\
\hline $\begin{array}{l}\text { Service(s) available to non- } \\
\text { residents (foreign clients) }\end{array}$ & & No & Yes & Yes \\
\hline
\end{tabular}

U3D=Université Dan Dicko Dankoulodo

AN2PI=Agence Nationale de la Propriété Industrielle et de la Promotion de l'Innovation

MDIAT=Ministère du Développement Industriel de l'Artisanat et du Tourisme

\footnotetext{
${ }^{6} \mathrm{http}: / / \mathrm{www}$. wipo.int/tisc/en/search/search_result.jsp?country_code=NE accessed on 15/10/2017

${ }^{7}$ We also found that another TISC had been created at Abdou Moumouni University of Niamey, but this information seems to be not available online.

${ }^{8}$ Maradi is the economic capital city and Niamey is the politic and administrative capital city of Niger.

${ }^{9}$ Potential users include: individual inventors, small and medium enterprises, industry, researchers in technology centers and universities, academia (ranging from schools to universities), IP professionals, etc.
} 


\subsubsection{Technical Assistance Database}

From 2009 to 2016, IP Technical Assistance Database search results highlighted around 84 records ${ }^{10}$ related to IP strategies, Support to Operations of IP offices, Legislative and Policy advice, Capacity building. This database published as Open Data is certainly a key component for all stakeholders and will enhance transparency and accountability of IP offices.

\section{Case study: Tabtakey Project}

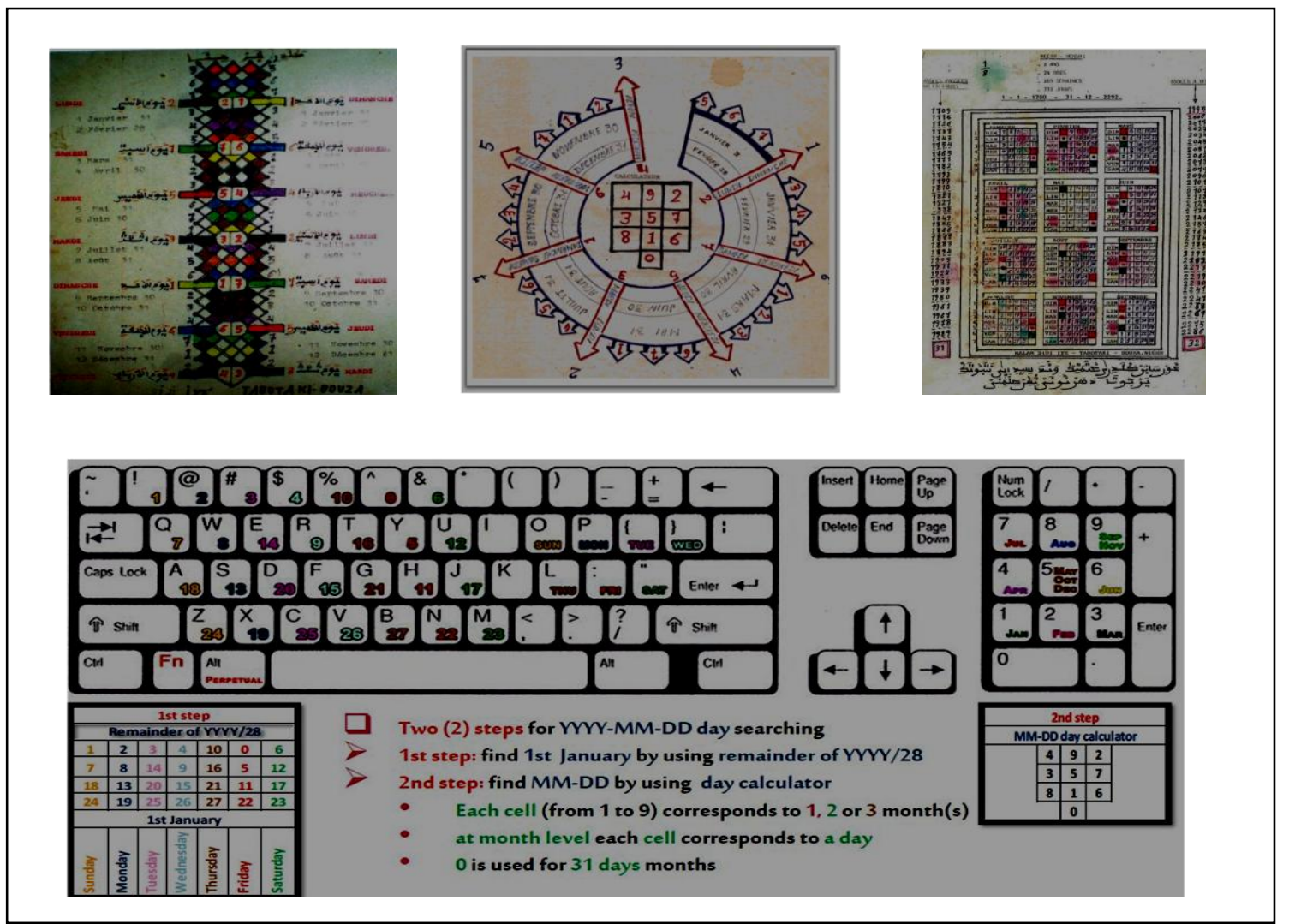

Fig. 2. Overview of different creations by Malam Sidi Iyé (3 top pictures) and his grandson Dr Ibrahim Sidi Zakari (Computer Keyboard).

The top three (3) pictures in Figure 2. have been created by Malam Sidi Iyé ${ }^{11}$ (from early 1950 to 1980) and contributed to the edition of a perpetual Gregorian calendar covering 600 years period (from 1st January 1701 to 31 December 2300) with years classification (depending on the number of days of February) and corresponding user guide. The last picture

\footnotetext{
${ }^{10} \mathrm{http}: / / \mathrm{www}$.wipo.int/tad/en/activitysearchresult.jsp?bcntry=NE accessed on 15/10/2017

${ }^{11}$ See Introduction of this paper for the context and additional chronological background information.
} 
(computer keyboard named Tabtakey) has been designed by Dr Ibrahim Sidi Zakari, when participating (as Next Einstein Forum's Ambassador) to the Challenge from Invention to Innovation (NEF Global Gathering, Dakar, Senegal, 2016). These pictures highlight a typical case of invention followed by incremental tradition based innovation in the field of mathematics and ICT. More generally, the invention to innovation process can be explained as The continuum from problem $\rightarrow$ to knowledge $\rightarrow$ to imagination $\rightarrow$ to innovation $\rightarrow$ to intellectual property and finally $\rightarrow$ to the solution in the form of products (see [11]). The pictures include: a vertical calculator for dates searching, a circular calculator for dates searching, an ancient calendar (corresponding to one of the 14 tables designed by Malam Sidi Iyé) with years classification and a computer keyboard including a two steps mathematical algorithm for dates searching. Globally, the framework (as a codified traditional knowledge) benefited of regional patent application (in the early 1990), a national protection (since 2013) and some elements are currently under the Creative Commons license CC BY-NC-ND 4.0 (AttributionNonCommercial-NoDerivatives 4.0 International) as a gallery dedicated to Open Mathematics $^{12}$. To view a copy of the license, please visit https://creativecommons.org/licenses/by-nc-nd/4.0/

Furthermore, Tabtakey can be used for promoting lifelong learning (alphabetization, arithmetics, probability, statistics, algorithmic, programming,...). As a standalone device, it is adpated for rural and urban areas. Physical and virtual (software or mobile app) options can be implemented.

In terms of perspectives, Tabtakey project is planing to take into account persons with disabilities, reducing environmental impact by using recycled paper for printing the second edition of the perpetual calendar of Malam Sidi Iyé and 3D printing prototyping. These perspectives will certainly be materialized through the new Technology, Innovation and Business Incubator, IP services and IP-Policy ${ }^{\mathbf{1 3}}$ available at Abdou Moumouni University.

The project is still looking for business and technological partners, and planing innovative fundraising campaigns via online crowdfunding platforms and new possibilities offered by the FARSIT fund created in Niger in 2011.

Finally, we hope this transdisciplinary research will inspire new generations of inventors and innovators so that they can learn from the past in order to create the future.

Acknowledgments. The authors wish to thank representatives of The Next Einstein Forum Ambassadors Program, The Mandela Washington Fellowship for Young African Leaders Initiative, The Florida International University, Campus France, Lille 1 University and CEAMITIC (Centre d'Excellence Africain en Mathématiques, Informatique et TIC). Their support is greatly appreciated.

\section{Conclusion}

As shown by empirical facts and historical data, many opportunities are available at national, regional or international level for making IP system as enabler of sustainable development in Niger. To achieve the full potential of IP, continuous innovation is required at all levels and all fields, particularly in the field of traditional knowledge.

Empowering the general public for understanding the benefits of purchasing legitimate goods and services will contribute to boost local businesses and develop frugal innovation.

${ }^{12}$ See imaginary gallery

${ }^{13} \mathrm{http}: / / \mathrm{www}$.wipo.int/policy/en/university ip_policies/ 
On the research issue, Policy making should take into account the academics involved in fundamental or applied research and encourage them to extend their focus beyond the publications of papers in academic journals.

Awareness raising should be an inclusive and participatory process involving all of the stakeholders and aligned with the national and regional development strategies. The recent national initiatives like the Niger 2.0 and Smart Villages will certainly improve the access and use of the ICT in Niger, particularly in rural areas where the majority of traditional knowledge holders and young people are currently living, facts that will certainly contribute to the current national program of Cultural Renaissance. Regional and international competitions on Inventions and Innovations organized by the African Intellectual Property Organization (AIPO), African Regional Intellectual Property Organization (ARIPO) and the World Intellectual Property Organization (WIPO) will certainly contribute to find local solutions to local needs necessary for achieving the Agenda 2030 for Sustainable Development. Finally, the use of the Ishango bones (considered as one of the oldest mathematical artefact and also a lunar calendar), as an award for outstanding Young African Scientists, Technologists and Innovators during international events like the Next Einstein Forum, remind us that a new tradition based revolution from Africa becomes necessary.

\section{References}

[1] Iyé, S.: Manuel d'utilisation du calendrier permanent, unpublished manuscript, (1990)

[2] Republique du Niger, Ministère de la Jeunesse, des Sports et de la Culture : Calendrier Universel et permanent d'après Malam Sidi IYE, Du 01 janvier 1701 au 31 décembre 2300, (2013)

[3] Dutfield G.: The Public and Private Domains: Intellectual Property Rights in Traditional Knowledge Vol. 21, No.3, Science Communication, p. 278 (2000)

[4] Downes, D.: How Intellectual Property could be a Tool to Protect Traditional Knowledge, Columbia Journal of Environmental Law 25, pp. 253-282 (2000)

[5] Mugabe, J.: Intellectual Property Protection and Traditional Knowledge, Intellectual Property and Human Rights, WIPO (1999)

[6] WIPO: Intellectual Property Needs and Expectations of Traditional Knowledge Holders, WIPO

Report on Fact-finding Missions on lntellectual Property and Traditional Knowledge, Geneva (2001)

[7] WIPO: Intellectual Property Handbook, Geneva (2004)

[8] Johnson P.S.: The Economics of Invention and Innovation, Durham University, UK (1975)

[9] Alikhan, S.: The Role of Intellectual Property in Economic Development, WIPO (1997)

[10] Alikhan, S.: Socio-Economic Benefits of Intellectual Property Protection in Developing Countries, WIPO Pub. No. 454 (2000)

[11] Kamil I.: Intellectual Property, A Power Tool for Economic Growth, WIPO (2003)

[12] Aghion, P., P.A. David et D. Foray.: Science, Technology and Innovation for Economic Growth: Toward Linking Policy Research and Practice in «STIG» Systems, Stanford Institute for Economic Policy Research, Document de travail No. 06-39, Université de Stanford, Stanford (2007)

[13] Nwuke, K.: Science, Technology and Innovation Policy in Africa in the Age of Brilliant and Disruptive Technologies: An Analysis of Policies at the National, Regional and Continental Levels, Document d'information pour ARIA VII. Commission économique pour l'Afrique (2015)

[14] WIPO: Breakthrough technologies -Semiconductor, innovation and intellectual property, Economics \& Statistics Series (2015)

[15] WIPO: World Intellectual Property Indicators 2016, Economics and Statistics Series, (2016)

[16] Cornell University, INSEAD, and WIPO: The Global Innovation Index 2017: Innovation Feeding the World, Ithaca, Fontainebleau, and Geneva (2017) 